\title{
Hemicrania continua and unilateral headaches: are they still together in the IHS classification?
}

\author{
Fabio Antonaci ${ }^{1 *}$, Ottar Sjaastad ${ }^{2}$, Torbjorn A Fredriksen ${ }^{3}$ \\ From Abstracts from the 1st Joint ANIRCEF-SISC Congress \\ Rome, Italy. 29-31 October 2015
}

Sjaastad \& Spierings described "Hemicrania continua" (HC) in 1984 [1]. In 2001, succinct criteria were presented [2]: permanent hemicrania, pain intensity: mild-moderate, (but occasionally - severe) and indomethacin dosage < $150 \mathrm{mg}$ daily. In addition, relative shortage of "local" autonomic phenomena, relative lack of "migraine symptoms" and of "cervicogenic" features. Such patients generally had tried legion drugs, with little effect. Such trials equal the usage of placebo. These guidelines seemed to function close to optimally. Then, criteria of the International Headache Society (IHS) (ICHD-III beta classification) came along. Surprisingly, they were transferred from a recent review article by Goadsby [3], almost word by word, despite the existence of a committee of intelligent and knowledgeable colleagues. There is an abundance of failures in the actual scheme. It is unacceptable to include as mandatory criteria, facial/forehead autonomic features. In this way, e.g. sweating becomes prominent - 33\%, against a subjective feeling of sweating in only $6 \%$ of our series (ratio: 5.5). Objectively, by quantitative evaporimetry, there was no facial asymmetry in all our 8 cases. There were 12 autonomic phenomena in this category [3], with a mean ratio between Goadsby's/our figures of 4.4. When made mandatory, autonomic features will create bogus cases. Bogus cases necessitate ultra-high indomethacin dosages; such dosages have an unspecific, analgesic effect, on various headaches. Our mean indomethacin continuation dosage was: $83 \mathrm{mg}$ (range: 50-150), while in Goadsby's series it was $176 \mathrm{mg}(25-500)$. HC is the unilateral headache with the least "local" autonomic features, "migrainous" and "vascular" components. It is a rather "pure" headache. The present classification brings HC

\footnotetext{
* Correspondence: fabio.antonaci@unipv.it

${ }^{1}$ Headache Centre, C. Mondino National Institute of Neurology Foundation, IRCCS, Department of Brain and Behavioral Sciences, University of Pavia Pavia, Italy

Full list of author information is available at the end of the article
}

nearer to other unilateral headaches with local autonomic symptoms, a misunderstood policy. $\mathrm{CPH}$ is exceptional with clinical similarities; the absolute indomethacin effect suggests a shared, core pathogenesis.

\section{Authors' details}

'Headache Centre, C. Mondino National Institute of Neurology Foundation, IRCCS, Department of Brain and Behavioral Sciences, University of Pavia, Pavia, Italy. ${ }^{2}$ Department of Neurology, St. Olavs Hospital, Trondheim University Hospitals, NTNU, Trondheim, Norway. ${ }^{3}$ Department of Neurosurgery, St. Olavs Hospital, Trondheim University Hospital, Trondheim, Norway.

\section{Published: 28 September 2015}

\section{References}

1. Sjaastad O, Spierings EL: Hemicrania continua. Another headache absolutely responsive to indomethacin. Cephalalgia 1984, 4:65-70.

2. Pareja JA, Vincent M, Antonaci F, Sjaastad O: Hemicrania continua: diagnostic criteria and nosologic status. Cephalalgia 2001, 21:874-877.

3. Cittadini E, Goadsby P: Hemicrania continua: A clinical study of 39 patients with diagnostic implications. Brain 2010, 133:1073-1986.

doi:10.1186/1129-2377-16-S1-A35

Cite this article as: Antonaci et al:: Hemicrania continua and unilateral headaches: are they still together in the IHS classification? The Journal of Headache and Pain 2015 16(Suppl 1):A35.

\section{Submit your manuscript to a SpringerOpen ${ }^{\circ}$ journal and benefit from: \\ - Convenient online submission \\ - Rigorous peer review \\ - Immediate publication on acceptance \\ - Open access: articles freely available online \\ - High visibility within the field \\ - Retaining the copyright to your article}

Submit your next manuscript at $>$ springeropen.com creativecommons.org/licenses/by/4.0), which permits unrestricted use, distribution, and reproduction in any medium, provided the original work is properly cited. The Creative Commons Public Domain Dedication waiver (http://creativecommons.org/publicdomain/ zero/1.0/) applies to the data made available in this article, unless otherwise stated. 